( 2021 , The Authors. Published by Elsevier Inc. and Fass Inc. on behalf of the American Dairy Science Association ${ }^{\circledR}$. This is an open access article under the CC BY-NC-ND license (http://creativecommons.org/licenses/by-nc-nd/4.0/).

\title{
All-trans retinoic acid controls differentiation, proliferation, and lipolysis in isolated subcutaneous adipocytes from peripartal Holstein cows
}

\author{
Qiushi Xu, ${ }^{1 *}$ ๑ Yunhui Fan, ${ }^{1 *}$ Juan J. Loor, ${ }^{2}$ ๑ Yusheng Liang, ${ }^{2} \odot$ Xudong Sun, ${ }^{1}$ Hongdou Jia, ${ }^{1}$ Chenxu Zhao, ${ }^{1}$ \\ and Chuang $\mathrm{Xu}^{1} \dagger$ ( \\ ${ }^{1}$ College of Animal Science and Veterinary Medicine, Heilongjiang Bayi Agricultural University, Daqing 163319, China \\ ${ }^{2}$ Mammalian NutriPhysioGenomics, Department of Animal Sciences and Division of Nutritional Sciences, University of Illinois, Urbana 61801
}

\begin{abstract}
Preadipocyte proliferation and differentiation are critical for normal adipose tissue development, including achieving a mature phenotype, characterized by its ability to accumulate triacylglycerol and release fatty acids. In nonruminants, it is well known that all-trans retinoic acid (ATRA), the most-active form of vitamin A, helps regulate proliferation, differentiation, and apoptosis in several types of cells including adipocytes. The purpose of this study was to evaluate the effect of ATRA on proliferation, apoptosis, differentiation, and lipolysis of primary bovine adipocytes isolated from subcutaneous adipose tissue of 5 healthy Holstein cows at 17 ( \pm 4 standard deviations $)$ d postpartum. Cells were stimulated with increasing concentrations of ATRA $(0.2,2$, and $20 \mathrm{n} M)$ at the preconfluent $(2 \mathrm{~d})$ and postconfluent $(8 \mathrm{~d})$ preadipocyte stage or at the mature adipocyte stage $(2 \mathrm{~d})$. All concentrations of ATRA inhibited preconfluent preadipocyte proliferation with decreased proportion of S-phase cells and reduced protein abundance of cyclins (CCND1, CCND2, CCND3, CCNE1) and cyclin-dependent kinases (CDK2, CDK4, CDK6). Compared with vehicle, ATRA treatment induced apoptosis in preconfluent preadipocytes. Additionally, ATRA $(0.2,2$, and $20 \mathrm{n} M)$ supplementation also inhibited differentiation of postconfluent preadipocytes through downregulation of protein abundance of PPAR $\gamma$ and $\mathrm{C} / \mathrm{EBP} \alpha$. After induction of differentiation, basal lipolysis in mature adipocytes increased upon treatment with all concentrations of ATRA. However, data on phosphorylated hormone-sensitive lipase or PLIN1 indicated that ATRA had no effect on
\end{abstract}

Received August 3, 2020.

Accepted November 5, 2020.

*These authors contributed equally to this work.

†Corresponding author: xuchuang7175@163.com epinephrine-stimulated lipolysis in mature adipocytes. Overall, these results demonstrate that ATRA might inhibit lipid accumulation by suppressing preadipocyte proliferation and differentiation, subsequently leading to apoptosis in postconfluent preadipocytes and promoting basal lipolysis in mature adipocytes. Overall, these in vitro responses provide some insights into the potential for nutritional management to modulate adipose tissue lipolysis, particularly in overconditioned cows during the dry period, which are more susceptible to suffer metabolic disorders due to excessive fat mobilization postpartum.

Key words: all-trans retinoic acid, proliferation, apoptosis, differentiation, bovine preadipocyte

\section{INTRODUCTION}

High body condition or excess fat accumulation before parturition is associated with the development of "fat cow syndrome," which is characterized by depression, anorexia, hyperketonemia, and marked decrease in milk production (Morrow, 1976). Human and rodent obesity models demonstrated that adipose tissue development depends on adipocyte hypertrophy (increases in cell size) and hyperplasia (increases in cell number; Montague and O'Rahilly, 2000; Hausman et al., 2001). The number of adipocytes is thought to increase as a result of the proliferation of preadipocytes and their subsequent differentiation into mature adipocytes (Spiegelman and Flier, 1996). Both proliferation and differentiation of preadipocytes are characterized by marked changes in the pattern of transcriptional and posttranslational responses that are achieved by sequential induction of various transcription factors (McNamara and Huber, 2018). Although studies have characterized transcriptome profiles associated with diet-induced adipose deposition in dairy cows (Moisá et al., 2017; Minuti et al., 2020), little is known about cellular and molecular mechanisms that regulate proliferation and differentiation in bovine preadipocytes. 
Vitamin A is a nutrient with remarkable effects on adipose tissue biology and energy homeostasis (Bonet et al., 2003). Dietary vitamin A and pro-vitamin A are stored as retinyl esters or metabolized intracellularly to retinoic acid (RA), the main active form of vitamin A (Blomhoff and Blomhoff, 2006). Accumulating evidence indicates that specific retinoids, such as RA, affect developmental and biochemical processes by influencing mammalian adiposity, including adipocyte differentiation (adipogenesis), lipogenesis, lipolysis, and fatty acid oxidation (Bonet et al., 2012). There are 2 isoforms of RA, all-trans RA (ATRA) and 9-cis RA, which exert their effects on cell processes through both genomic and nongenomic mechanisms by binding to retinoid receptors and their heterodimers (Theodosiou et al., 2010). At least in nonruminants, adipose tissue is the second most important site of vitamin A storage and metabolism after the liver, as well as the main target of ATRA action (Landrier et al., 2012). In humans, administration of ATRA results in reduced body weight and adiposity (Bonet et al., 2003). Additionally, ATRA inhibits potently differentiation of clonal preadipocyte cell lines in vitro (Brandebourg and $\mathrm{Hu}$, 2005). High concentrations of ATRA also inhibit differentiation of 3T3-L1 preadipocytes (Green and Kehinde, 1975; Schwarz et al., 1997; Berry et al., 2012). The inhibition of adipogenesis by ATRA is mediated by transcription factors linked to suppression of $\mathrm{C} /$ EBP (CCAAT/enhancer-binding protein) activity and induction of anti-adipogenic genes (Ribot et al., 2001; Mercader et al., 2006). Furthermore, ATRA reduced the capacity for lipogenesis, and directly increased lipolysis and reduced triacylglycerol content in mature 3T3-L1 adipocytes (Mercader et al., 2007). Whether these molecular mechanisms of ATRA are biologically relevant to proliferation and differentiation in bovine preadipocytes is unclear.

The present study was undertaken to test the hypothesis that ATRA regulates adipocyte proliferation and differentiation using a well characterized in vitro model system, which has been shown to recapitulate many physiological events that occur in vivo (Zhang et al., 2018; Sun et al., 2019; Xu et al., 2019a). We specifically explored the effect of ATRA on bovine preadipocyte proliferation, apoptosis, and differentiation, and mature adipocytes lipolysis.

\section{MATERIALS AND METHODS}

\section{Bovine Preadipocyte Isolation}

All animal procedures were performed in accordance with the Guidelines for Care and Use of Laboratory
Animals of Heilongjiang Bayi Agricultural University (Daqing, China) and approved by the Animal Ethics Committee of Heilongjiang Bayi Agricultural University (Protocol approval number: SY201809005). Holstein dairy cows selected in this experiment were from a 7,000-cow dairy farm with a freestall housing system located in Nenjiang (Heilongjiang, China). A total of 30 lactating Holstein cows (number of lactations: median $=3$, range $=2-4 ;$ DIM: median $=7 \mathrm{~d}$, range $=3-12$ d) were evaluated to identify healthy animals. Five cows with serum BHB concentrations below $1.2 \mathrm{mM}$ were selected for subsequent analyses (Vanholder et al., 2015). All cows were examined by the attending veterinarian to ensure there were no other complications such as hypocalcemia or mastitis. Subcutaneous adipose tissue (SAT) was collected from the tail-head of 5 healthy Holstein cows at $17( \pm 4)$ d postpartum (Xu et al., 2019b) and processed as described previously (Xu et al., 2019a). In brief, SAT (1 g) was digested with collagenase type I digestion solution $(1 \mathrm{mg} / \mathrm{mL}$; SigmaAldrich, St. Louis, MO) and then filtered through a $40-\mu \mathrm{m}$ cell filter (Solarbio, Beijing, China). Stromal vascular $(\mathbf{S V})$ cells were then centrifuged at $800 \times g$ for $10 \mathrm{~min}$ at room temperature and the supernatant discarded to separate primary preadipocytes from SV cells. Residual erythrocytes in the resulting cell pellet were eliminated by ACK lysis buffer (Solarbio) and then sequentially centrifuged at $800 \times g$ for $10 \mathrm{~min}$ at room temperature. Preadipocytes were obtained by outgrowth of plastic adherent cells from the SV cells after 2 serial passages in T25 cell culture flasks (Corning Costar Co., Corning, NY; Strieder-Barboza et al., 2018) in basic culture medium (BCM), which was Dulbecco's modified Eagle medium/F12 (DMEM/F12; HyClone, Logan, UT) supplemented with $10 \%$ fetal bovine serum (HyClone) and 1\% (vol/vol) penicillin-streptomycin (HyClone).

Initially, preconfluent preadipocytes were resuspended in BCM and $1.8 \times 10^{5}$ cells were seeded in each well of 6 -well plates (approximately 30\% confluency). To differentiate preconfluent preadipocytes, 4-d postconfluent cells at approximately $70 \%$ confluency were incubated in differentiation culture medium 1 (DCM1), containing 10\% fetal bovine serum (HyClone), $1 \%$ penicillin-streptomycin, $0.5 \mathrm{mM}$ 3-Isobutyl1-methylxanthin (Sigma-Aldrich), $1 \mu M$ dexamethasone (Sigma-Aldrich), and $1 \mu \mathrm{g} / \mathrm{mL}$ insulin (Sigma-Aldrich) in $500 \mathrm{~mL}$ BCM. After $4 \mathrm{~d}$ of incubation, DCM1 was replaced by maintenance medium containing $10 \%$ fetal bovine serum, $1 \%$ penicillin-streptomycin, and $1 \mu \mathrm{g} /$ $\mathrm{mL}$ insulin in $500 \mathrm{~mL}$ DMEM/F12. After $2 \mathrm{~d}$ of incubation, the maintenance medium was replaced with BCM, with the endpoint of the experiment being $\mathrm{d}$ 8. On $\mathrm{d}$ 
8, intracellular triglycerides were stained by Oil Red $\mathrm{O}$, and adipocytes were counter-stained with hematoxylin and photographed with a light microscope as described previously (Zhang et al., 2018; Xu et al., 2019a). The detailed grouping is described in the figure legends.

\section{MTS Proliferation Assay}

The MTS Cell Proliferation and Cytotoxicity Assay Kit (C0009, Beyotime Institute of Biotechnology, Jiangsu, China) was used to evaluate cell viability according to the manufacturer's instructions. For preconfluent preadipocytes, cells were seeded at a density of 2 $\times 10^{4}$ cells per 96 wells plates, and ATRA $(0.2,2,20$, and $200 \mathrm{nM}$ ) dissolved in dimethyl sulfoxide or vehicle (dimethyl sulfoxide only) were added at $48 \mathrm{~h}$ after cell seeding for an additional $48 \mathrm{~h}$. For postconfluent preadipocytes, ATRA $(0.2,2,20$, and $200 \mathrm{n} M)$ was added with DCM1 differentiation medium at $\mathrm{d} 0$ followed by incubation for an additional $8 \mathrm{~d}$. The culture medium with ATRA was replenished every $48 \mathrm{~h}$. For mature adipocytes, ATRA $(0.2,2,20$, and $200 \mathrm{n} M)$ was added with BCM culture medium at d 8 of differentiation followed by an additional $48 \mathrm{~h}$ of incubation. Absorbance was measured at $570 \mathrm{~nm}$ using a 96-well plate reader (Multiskan FC; Thermo Fisher Scientific Inc., Waltham, MA). Results are expressed as a percentage of the control value.

\section{Cell Cycle Analysis}

Preconfluent preadipocytes were synchronized by serum starvation for $12 \mathrm{~h}$ and subsequently treated as described above. At the end of treatment, cells were harvested by trypsinization, centrifuged at 1,000 $\times g$ for $5 \mathrm{~min}$ at room temperature, washed with PBS, and then fixed overnight at $4^{\circ} \mathrm{C}$ in $70 \%$ ethanol. Fixed cells were washed with $\mathrm{PBS}$ and stained with $0.5 \mathrm{~mL}$ of PI/RNase staining buffer (BD Biosciences, San Jose, CA) for $15 \mathrm{~min}$ at room temperature. Stained cells were analyzed by flow cytometry (BD FACSCalibur; BD Biosciences).

\section{Annexin V and Propidium lodide Staining Assay}

Preconfluent preadipocytes apoptosis was detected via annexin V-fluorescein isothiocyanate (FITC) and propidium iodide (PI) double staining using FITC Annexin V Apoptosis Detection Kit I (BD Biosciences) according to the manufacturer's instructions. The fluorescence was measured by flow cytometry (BD FACSCalibur; BD Biosciences). Annexin $\mathrm{V}^{+} / \mathrm{PI}^{+}$[quadrant (Q)2] double-stained cells were considered as late apop- totic, and Annexin $\mathrm{V}^{+} / \mathrm{PI}^{-}(\mathrm{Q} 4)$ cells were considered as early apoptotic. The percentage of apoptotic cells was calculated as the sum of Q2 + Q4 cells.

\section{ELISA-Based Apoptosis Assay}

Degree of apoptosis in preconfluent preadipocytes was measured using an APOSTRAND ELISA apoptosis detection kit (Enzo Life Sciences, Farmingdale, NY) according to the manufacturer's protocols and measured using a microplate reader (Multiskan FC; Thermo Fisher Scientific Inc.) at $405 \mathrm{~nm}$. Apoptosis data from pre-adipocytes plated on vehicle or ATRA $(0.2,2,20$, and $200 \mathrm{nM})$ were normalized to positive control of single-stranded DNA (ELISA detect singlestranded DNA as a marker of apoptosis) and viable cell number.

\section{Western Blot Analysis}

Western blotting was performed as previously described (Sun et al., 2019). Briefly, total protein was extracted from adipocytes using a Cell Total Protein Extraction Kit according to the manufacturer's instructions (C510003-0050, Sangon Biotech, Shanghai, China). Total protein concentration was measured by the BCA method (C503051-0500, Sangon Biotech). A total of $30 \mu \mathrm{g}$ of protein from each sample was separated by $12 \%$ SDS-PAGE with known molecular weight markers (Sangon Biotech). Subsequently, the protein was transferred onto $0.45-\mu \mathrm{m}$ polyvinylidene difluoride membranes. The polyvinylidene difluoride membranes were incubated with primary antibodies against CCND1 (1:2,000; ab226977; Abcam, Cambridge, UK), CCND2 (1:1,000; ab230883, Abcam), CCND3 (1:2,000; ab155682; Abcam), CCNE1 (1:2,000; ab33911; Abcam), CDK2 (1:1,000; ab235941; Abcam), CDK4 (1:500, ab137675; Abcam), CDK6 (1:1,000, ab151247; Abcam), PPAR $\gamma$ (1:500; ab45036; Abcam), C/EBPa (2 $\mu \mathrm{g} / \mathrm{mL}$; ab15047; Abcam), phosphorylation of LIPE (1: 1,000; \#4139; Cell Signaling Technology Inc., Danvers, MA), LIPE (1 $\mu \mathrm{g} / \mathrm{mL}$; ab45422; Abcam), PLIN1 (1: 2,000 ; ab3526; Abcam), and $\beta$-actin $(1 \mu \mathrm{g} / \mathrm{mL}$; ab8226; Abcam) at $4^{\circ} \mathrm{C}$ overnight. Membranes were then washed with Tris-buffered saline with Tween (TBST) and incubated with the following secondary antibodies: horseradish peroxidase-conjugated Affinipure goat anti-mouse $\operatorname{IgG}\left(\mathrm{H}^{+} \mathrm{L}\right)$ (SA00001-1, 1:8,000; Proteintech) or horseradish peroxidase-conjugated Affinipure goat anti-rabbit $\operatorname{IgG}\left(\mathrm{H}^{+} \mathrm{L}\right) \quad(\mathrm{SA} 00001-1, \quad$ 1:8,000; Proteintech) at room temperature for $1 \mathrm{~h}$ followed by washed with TBST. Immunoreactive bands were then made visible by an enhanced chemiluminescence solu- 
tion (ECL, Millipore, Bedford, MA). $\beta$-Actin (ACTB) was used as a loading control. Last, ImageJ analysis software (version 1.8.0; Wayne Rasband, National Institutes of Health, Bethesda, MD) was used to quantify the maximum intensity of each band.

\section{Co-Immunoprecipitation Assay}

Co-immunoprecipitation (Co-IP) assays were used to separate the phosphorylated PLIN1 (p-PLIN1) using Pierce Co-IP Kit (cat. no. 26149; Thermo Fisher Scientific) as previously described (Xu et al., 2019b). A portion of the same adipocyte samples used for western blot analysis was washed with ice-cold PBS and lysed in Co-IP lysis buffer. The supernatant was collected after centrifugation at $12,000 \times g$ for $30 \mathrm{~min}$ at $4^{\circ} \mathrm{C}$. A small portion of the total lysate was used for determining protein expression levels, and all remaining lysates were used for Co-IP by adding PKA $(1 \mu \mathrm{g} / \mathrm{mL}$; 06-903; EMD Millipore Inc., Hong Kong, China) and protein A/G beads to separate the p-PLIN1 from total protein. After mixing overnight at $4^{\circ} \mathrm{C}$, the beads were precipitated and the supernatant removed. The beads were further washed 3 times with Co-IP lysis buffer, and the protein on the beads extracted by adding protein loading buffer and boiling. The extracted protein was used to detect the abundance of p-PLIN1 by western blot using PLIN1 (1: 2,000; ab3526; Abcam) antibody as described above.

\section{Lipolysis Assay}

Fully differentiated bovine adipocytes were treated with vehicle or ATRA $(0.2,2,20 \mathrm{n} M)$ with or without epinephrine $(1 \mu \mathrm{mol} / \mathrm{L})$. The dose and time point were chosen from a preliminary test, and it was within the linear range of glycerol release. The culture medium was removed from each well and assayed for glycerol content with a free glycerol determination kit (FG0100, Sigma-Aldrich). The increase in absorbance at $540 \mathrm{~nm}$ was directly proportional to the free glycerol concentration of the sample.

\section{Statistical Analysis}

Each experiment was repeated at least 3 times. All data were analyzed using the appropriate statistical analysis methods with the statistical package for the SPSS software version 25.0 (IBM, Armonk, NY) and GraphPad Prism program (Prism 8.3.0; GraphPad Software, San Diego, CA). In the dose-response study, orthogonal polynomial contrast analysis was conducted to evaluate the effects of ATRA on all response criteria except for controls. All data were tested for normality and homogeneity of variance using the Shapiro-Wilk and Levene tests, respectively. For data with Gaussian distribution, parametric statistical analysis was performed using the independent-samples $t$-test for 2 groups; 1-way ANOVA was performed for multiple comparisons with Bonferroni correction. A $P$-value $<$ 0.05 was considered statistically significant, and a $P$ value $<0.01$ was considered highly significant.

\section{RESULTS}

\section{Effects of ATRA on Preadipocyte and Adipocyte Viability}

The MTS cell viability and cytotoxicity assay indicated a significant increase in cell viability in both preand postconfluent preadipocytes stimulated with 0.2
A

A

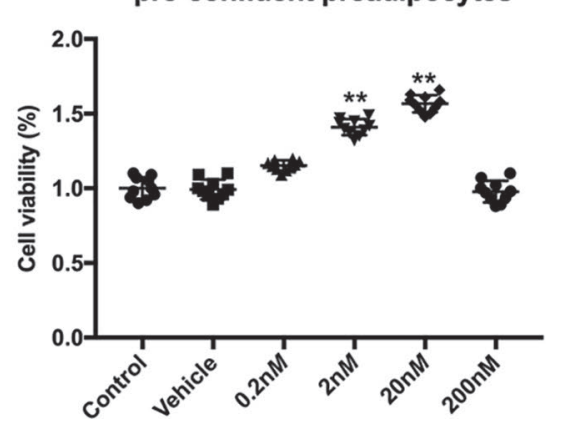

B

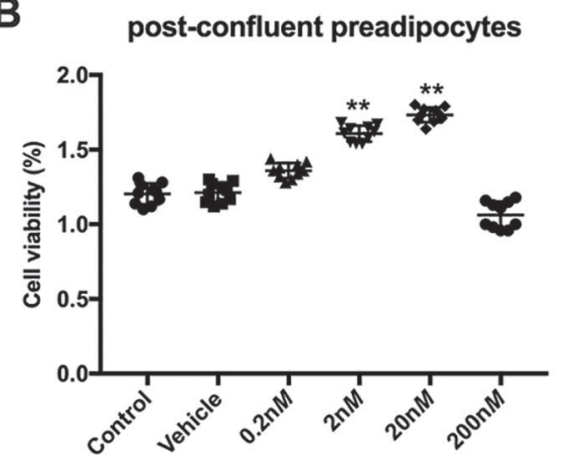

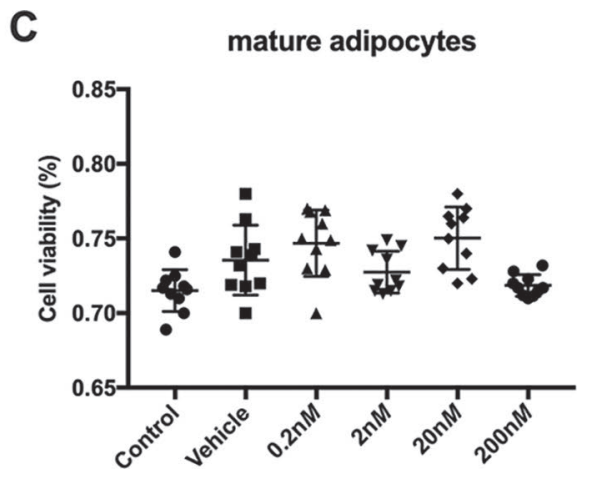

Figure 1. Effects of all-trans retinoic acid (ATRA) on preadipocyte and adipocyte viability. (A) Effects of ATRA on preconfluent preadipocyte viability. Preconfluent cells were treated with ATRA $(0.2,2,20$, and $200 \mathrm{n} M)$ at $2 \mathrm{~d}$ after cell plating. (B) Effects of ATRA on postconfluent preadipocyte viability. In postconfluent cells, ATRA was added with the DCM1 differentiation medium at d 0. (C) Effects of ATRA on mature adipocyte viability. The ATRA was added with the basic culture medium at d 8 of differentiation. After $48 \mathrm{~h}$ of treatment, cell viability was measured via the MTS assay. Comparisons among groups were calculated using Duncan's multiple comparisons to test for significance. Results represent means $\pm \mathrm{SEM} ;{ }^{*} P<0.05,{ }^{*} P<0.01$ for treatment versus control group. 
to $20 \mathrm{n} M$ ATRA $(P<0.01)$. Cell viability during the pre- and postconfluent proliferation and differentiation stages in preadipocytes did not differ between $200 \mathrm{n} M$ ATRA and the control (Figure $1 \mathrm{~A}$ and B). Treatment with ATRA $(0.2,2,20 \mathrm{n} M$, and $200 \mathrm{n} M)$ had no effect on cell viability in mature adipocytes (Figure 1C).

\section{Effects of ATRA on Proliferation and Cell Cycle}

Compared with vehicle, treatment with various concentrations of ATRA $(0.2,2$, and $20 \mathrm{n} M)$ reduced cell proliferation of preconfluent preadipocytes by downregulating the proportion of S-phase cells $(P<0.05$ and $P<0.01$, Figure $2 \mathrm{~A}$ and $\mathrm{B})$. Additionally, administration of ATRA to bovine preadipocytes downregulated protein abundance of CCND1, CCND2, CCND3, CCNE1, CDK2, CDK4, and CDK6 $(P<0.05$ and $P<$ 0.01, Figure 2C-E).

\section{Effects of ATRA on Preadipocyte Apoptosis}

Exogenous ATRA increased apoptosis with considerable effects on preadipocytes after treatment with 0.2 , 2 , and $20 \mathrm{n} M$ ATRA for $48 \mathrm{~h}(P<0.01$, Figure $3 \mathrm{~A}-\mathrm{E})$. Compared with the vehicle group, treatment with 20 $\mathrm{n} M$ ATRA induced a 2-fold increase in preadipocyte apoptosis $(P<0.01$, Figure $3 \mathrm{E})$. Similar results were obtained for the single-stranded DNA apoptosis assay
(Figure $3 \mathrm{~F}$ ) where treatment with various concentrations of ATRA $(0.2,2$, and $20 \mathrm{nM})$ significantly induced apoptosis in preconfluent preadipocytes $(P<$ 0.01, Figure 3F).

\section{Effects of ATRA on Differentiation}

Exogenous ATRA dose-dependently decreased lipid accumulation and lipid droplet size as assessed by Oil Red $\mathrm{O}$ staining of bovine preadipocytes on $\mathrm{d} 8$ of differentiation (Figure 4A). Compared with the vehicle group, ATRA treatment downregulated the abundance of PPAR $\gamma$ and $\mathrm{C} / \mathrm{EBP} \alpha$ at $\mathrm{d} 8$ of differentiation $(P<$ 0.01 , Figure $4 \mathrm{~B}$ and $\mathrm{C}$ ).

\section{Effects of ATRA on Adipocyte Lipolysis}

Compared with the vehicle, exogenous ATRA increased basal lipolysis in fully differentiated bovine adipocytes $(P<0.01$, Figure 5A). Free glycerol release into the culture medium was increased by $\sim 50$ (0.2 and $2 \mathrm{n} M$ ATRA) and 90\% (20 n $M$ ATRA), respectively, after $48 \mathrm{~h}$ of incubation. However, at all dosages used, ATRA had no effect on epinephrine-induced triglyceride hydrolysis characterized by free glycerol release (Figure $5 \mathrm{~B})$. Phosphorylation of LIPE or PLIN1 increased in response to epinephrine $(P<0.01)$, but no significant changes were observed in response to all concentrations of ATRA $(0.2,2$, and $20 \mathrm{n} M$; Figure $5 \mathrm{C}-\mathrm{E})$.

A
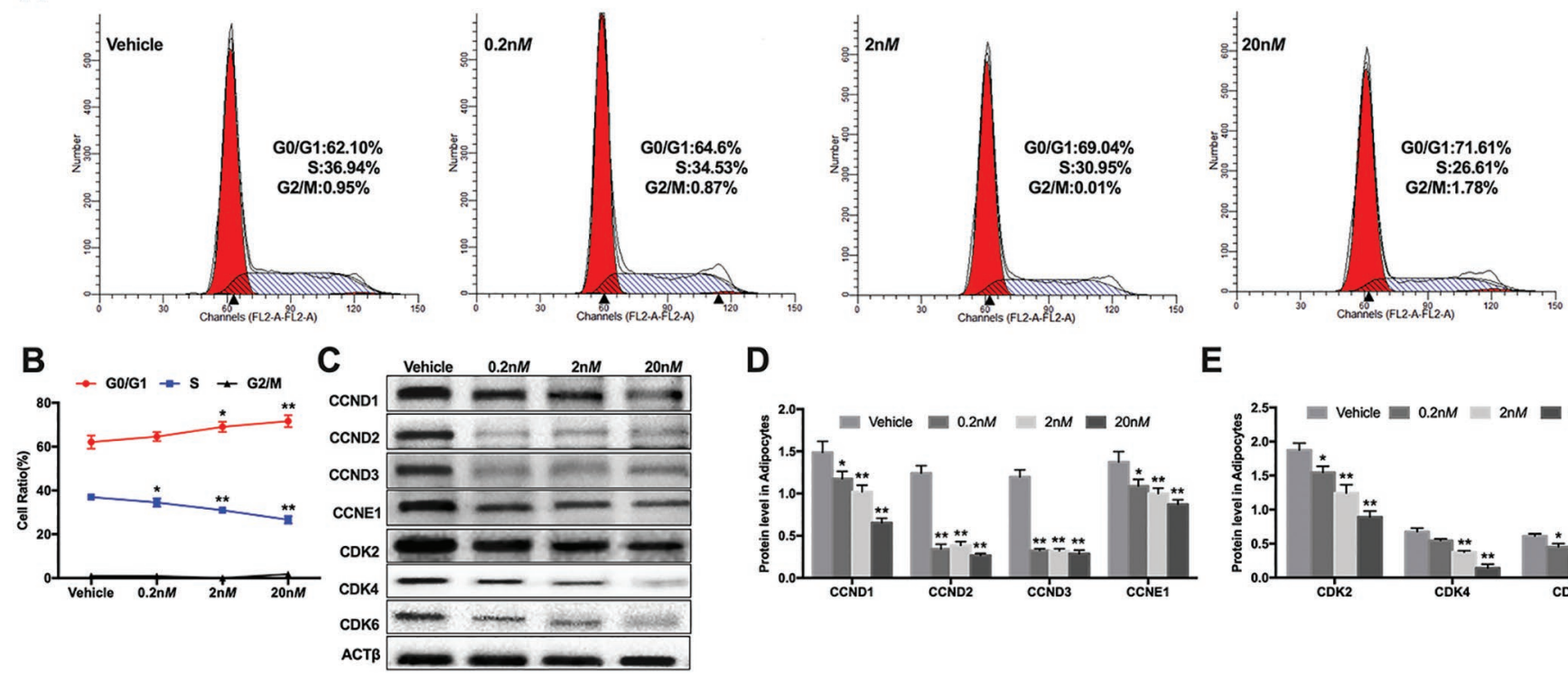

D

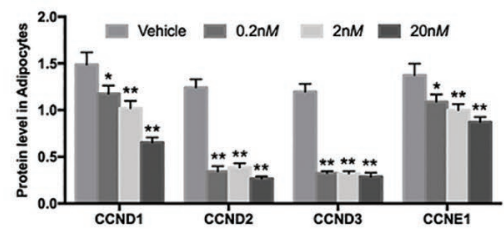

$\mathbf{E}$

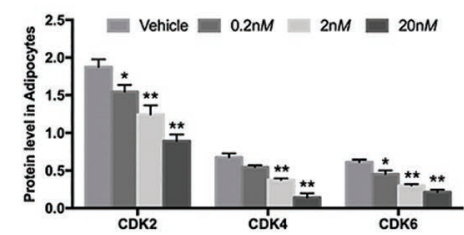

Figure 2. Effects of all-trans retinoic acid (ATRA) on proliferation and cell cycle in bovine preadipocytes. (A and B) Effects of ATRA on proliferation of bovine preadipocytes. After treatment with ATRA, cell cycle analysis by flow cytometry was performed. (C-E) Effects of ATRA on protein abundance of cyclins (CCND1, CCND2, CCND3, CCNE1) and cyclin-dependent kinases (CDK2, CDK4, CDK6). Comparisons among groups were calculated using a one-way ANOVA with subsequent Bonferroni correction. Results represent means \pm SEM; ${ }^{*} P<0.05,{ }^{* *} P$ $<0.01$ for treatment versus vehicle group. 
A

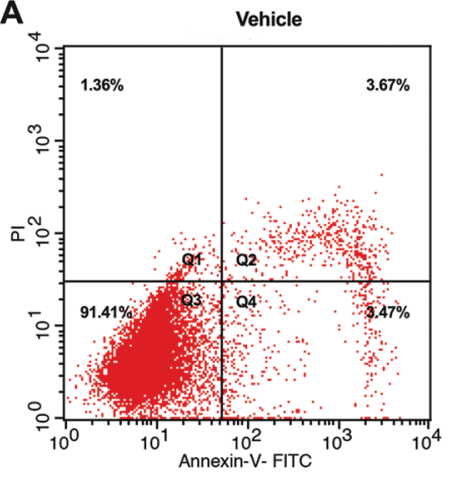

D

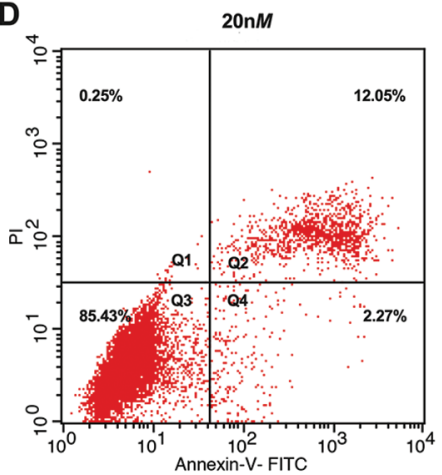

B

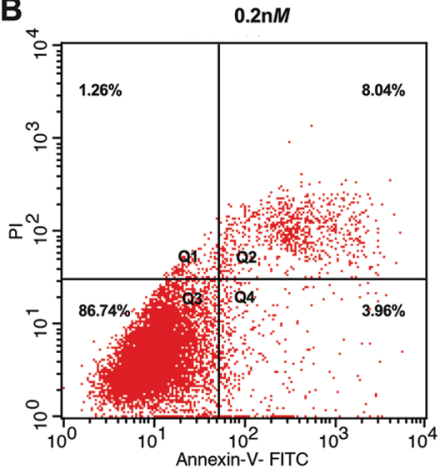

E

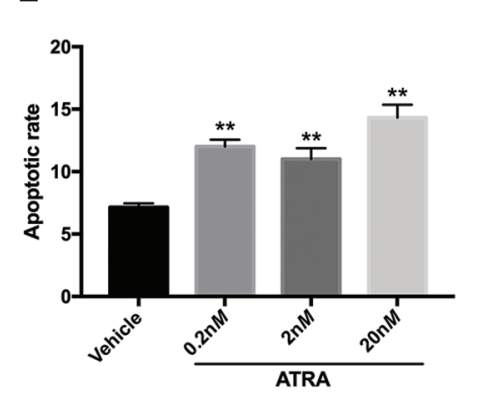

C

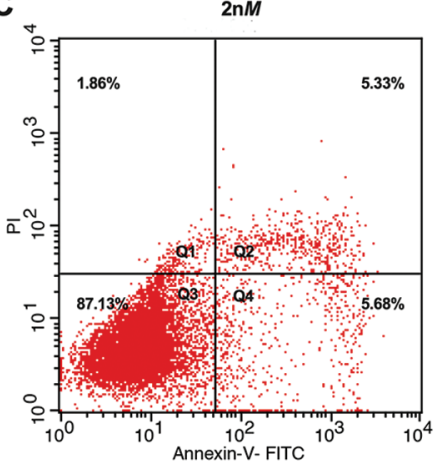

.

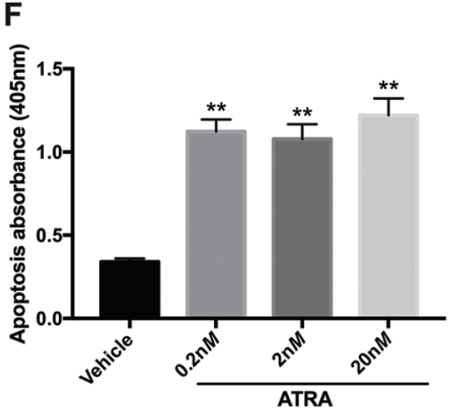

Figure 3. Effects of all-trans retinoic acid (ATRA) on apoptosis in preadipocytes. (A-E) Apoptosis rate of preconfluent preadipocytes. Wells were either vehicle or treated with 0.2 , 2, and $20 \mathrm{nM}$ ATRA, and cells were incubated for $48 \mathrm{~h}$. Quadrant (Q)1: necrotic cells [annexin V-fluorescein isothiocyanate (FITC) ${ }^{-}$/propidium iodide $(\mathrm{PI})^{+}$; Q2: late apoptotic cells (annexin V-FITC ${ }^{+} / \mathrm{PI}^{+}$); Q3: live cells $($annexin V-FITC ${ }^{-} / \mathrm{PI}^{-}$); Q4: early apoptotic cells (annexin $\mathrm{V}-\mathrm{FITC}^{+} / \mathrm{PI}^{-}$). The percentage of cells in Q1, Q2, Q3, and Q4 are shown. The percentage of apoptotic cells was calculated by adding Q2 + Q4 cells. (F) Level of apoptosis determined by single-stranded DNA ELISA. Amounts of apoptosis are expressed in arbitrary units. Comparisons among groups were calculated using a one-way ANOVA with subsequent Bonferroni correction. Results represent means $\pm \mathrm{SEM} ;{ }^{*} P<0.05,{ }^{* *} P<0.01$ for treatment versus vehicle group.

\section{DISCUSSION}

Overconditioned or "obese" cows experience depressed appetite around calving leading to a more severe state of negative energy balance (Hayirli et al., 2003), which partly explains their higher risks of metabolic disorders during the periparturient period. The antiobesity role of RA is well characterized in human and rodent obesity models (Ziouzenkova et al., 2007; Berry and Noy, 2009; Berry et al., 2012). The present study revealed that ATRA might suppress adipocyte development in 2 ways as follows: inhibition of adipocyte proliferation and differentiation, and prevention of lipid accumulation in adipocytes. Additionally, apoptosis in pre-confluent preadipocytes might partly contribute to the reduction of cellularity.

The effect of RA on proliferation and differentiation of cancer cells (Yang et al., 2001), osteoblasts (Wan et al., 2006), and myoblasts (Alric et al., 1998) is well established. Cell proliferation is dependent on 4 distinct phases of the cell cycle $\left(\mathrm{G}_{0}-\mathrm{G}_{1}, \mathrm{~S}, \mathrm{G}_{2}\right.$, and $\left.\mathrm{M}\right)$, with the $G_{1}$ to $S$ phase being regulated mainly by successive activation of several cyclin-dependent kinases. These proteins are expressed and active in a cell cycle phasespecific manner; for example, CDK4 and CDK6 activity is necessary for passage through $\mathrm{G}_{1}$, whereas CDK2 is active in the late $\mathrm{G}_{1}$ and $\mathrm{S}$ phase (Otto and Sicinski, 2017). In the current study, suppression of cell cycle transition from $\mathrm{G}_{1}$ to $\mathrm{S}$ phase and decreased abundance of CCND1, CCND2, CCND3, CCNE1, CDK2, CDK4, and CDK6 suggested that ATRA inhibited cell proliferation.

A previous study indicated that adipose-derived extracellular matrix components may affect adipose tissue expansion including pre-adipocyte proliferation, apoptosis, and adipogenesis (Halberg et al., 2008). Thus, we determined whether the antiproliferative property of ATRA influenced cell apoptosis by quantitative apoptosis assays. Our results reveled that all concentrations of ATRA increased apoptosis in preadipocytes. Considering that preconfluent bovine preadipocytes undergo several rounds of replication during the first $48 \mathrm{~h}$ of proliferation, the induction of apoptosis in preconfluent proliferating cells might be a potential mechanism by which ATRA attenuates adipogenesis, leading to fewer adipocytes. 
A
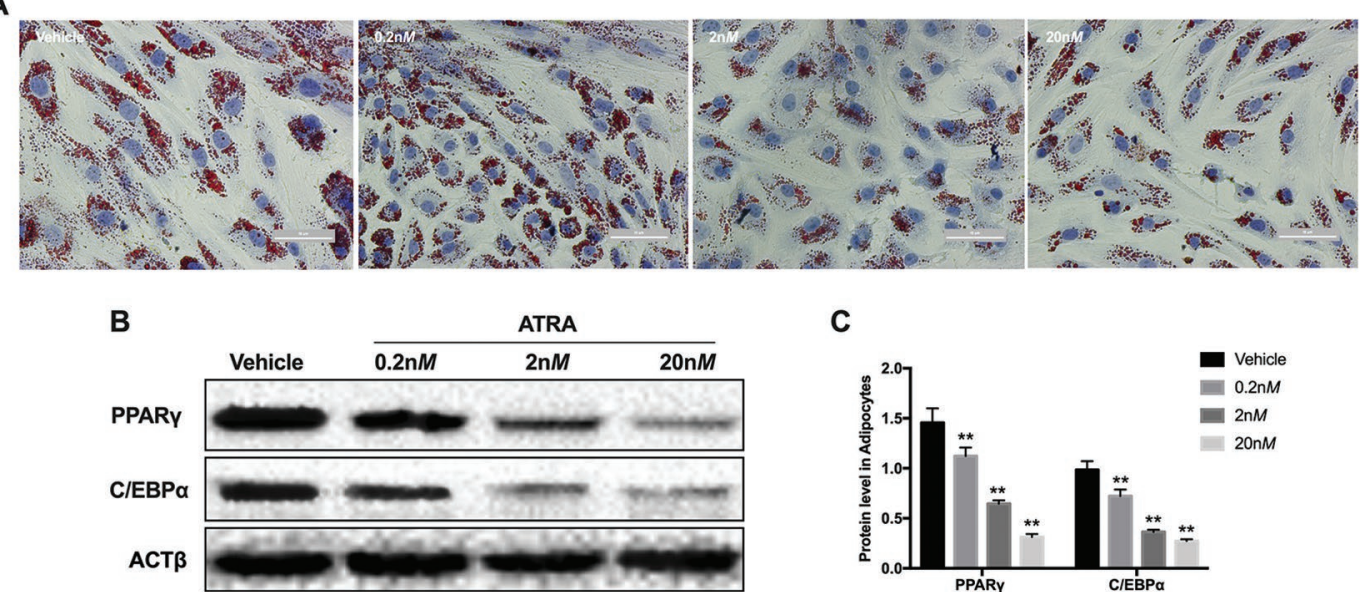

C

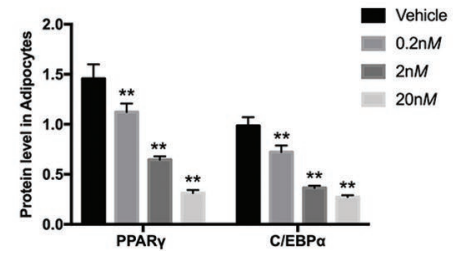

Figure 4. Effects of all-trans retinoic acid (ATRA) on differentiation of bovine preadipocytes. (A) Oil Red O staining of bovine preadipocyte cultures on d 8 of differentiation after treatment with ATRA $(0.2,2$, and $20 \mathrm{nM})$. (B-C) Western blot of known differentiation biomarkers $(\mathrm{PPAR} \gamma$ and $\mathrm{C} / \mathrm{EBP} \alpha)$ during differentiation at $\mathrm{d} 8$ after treatment with ATRA of bovine preadipocytes. Scale bar represents $10 \mu \mathrm{m}$. Comparisons among groups were calculated using a one-way ANOVA with subsequent Bonferroni correction. Results represent means \pm SEM; ${ }^{*} P<0.05,{ }^{* *} P<0.01$ for treatment versus vehicle group.

The MCF-7 human breast cancer cell line displayed a significantly decreased proportion of S-phase cells when treated with ATRA (Mangiarotti et al., 1998), which is consistent with our proliferation results of bovine preadipocytes. In confluent growth-arrested 3T3-L1 preadipocytes, an adipogenic stimulus initiates a limited clonal expansion before the cells enter the phase of terminal differentiation, including lipid accumulation (Gregoire et al., 1998; Otto and Lane, 2005). The transcription factor $\mathrm{C} / \mathrm{EBP} \alpha$ is required both for adipogenesis and for normal adipocyte function (Linhart et al., 2001), which promotes adipogenesis by inducing the expression of PPARG (Clarke et al., 1997), the master regulator of adipocyte differentiation (Ntambi and Young-Cheul, 2000; Lefterova and Lazar, 2009). In this regard, sequential induction of the transcription factors $\mathrm{C} / \mathrm{EBP} \alpha$ and PPAR $\gamma$ is necessary (Tontonoz et al., 1994). Thereafter, adipocyte-specific genes and enzymes are induced (Jump et al., 2006), and cell morphology is changed by reorganization of the cytoskeleton from a fibroblast-like appearance toward aspherical shape (Spiegelman and Farmer, 1982). Alltrans RA downregulated the expression of $P P A R G$ and $C E B P A$ in bovine preadipocytes, which agrees with the results observed in 3T3-L1 adipocytes (Nedergaard et al., 2005; Wang et al., 2014). Thus, available data indicate that ATRA might have a negative effect on adipogenesis.

Except for its anti-adipogenic effect, the present study also found that ATRA stimulated basal lipolysis when added to mature adipocytes. It was reported that lipolysis increases in 3T3-L1 adipocytes treated with ATRA (Dave et al., 2012). Furthermore, a previous study demonstrated that ATRA could activate both RA receptors and PPAR $\beta / \delta$, thereby enhancing lipolysis and depleting lipid stores in 3T3-L1 cells (Berry and Noy, 2009). Thus, increased lipid mobilization from adipocytes by basal lipolysis could be another reason for the reduction of body fat reported following ATRA treatment in rodents. In dairy cows, basal lipolysis rate increases steadily throughout lactation; concurrently, lipolysis is regulated mainly by adrenergic signaling in response to energy demands (McNamara and Hillers, 1986; Sumner and McNamara, 2007; De Koster et al., 2016).

In adipocytes under basal conditions, LIPE localizes in the cytosol and cannot access lipid droplets due to coating with PLIN (Brasaemle, 2007). However, under conditions of energy deficit that lead to adrenergic stimulation and a decrease in circulating insulin, both LIPE and PLIN are phosphorylated by PKA with further stimulation of lipolysis. Phosphorylated LIPE translocates from the cytosol and binds to lipid droplets via protein-protein interactions with p-PLIN1 (Brasaemle, 2007), which increases lipolysis rate up to 100-fold in nonruminants (Su et al., 2003; Yeaman, 2004). In the present study, treatment with epinephrine increased free glycerol release by approximately 1,500\% and upregulated phosphorylation of LIPE or PLIN1. However, no significant changes were observed on hydrolysis of triglycerides and markers of stimulated lipolysis following ATRA treatment in response to epinephrine stimulation. These observations indicated that ATRA had no effect on stimulated lipolysis in bovine adipocytes. Previous studies have shown that high genetic merit dairy cows have greater sensitivity to lipolysis, partly 
A

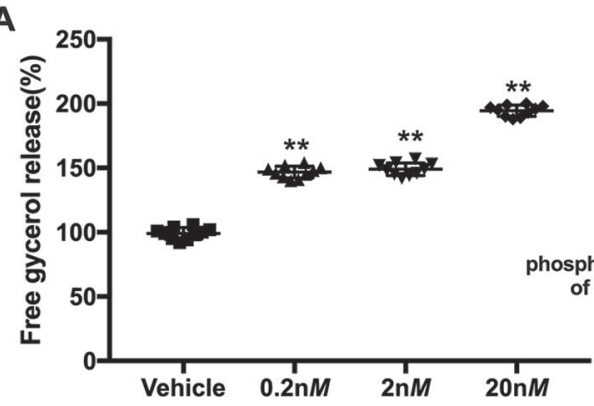

C

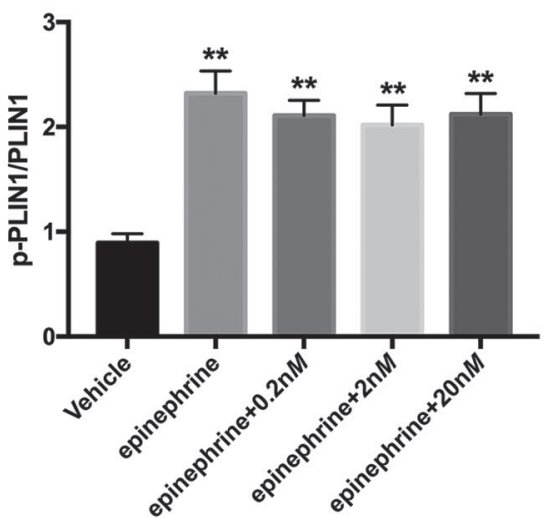

B
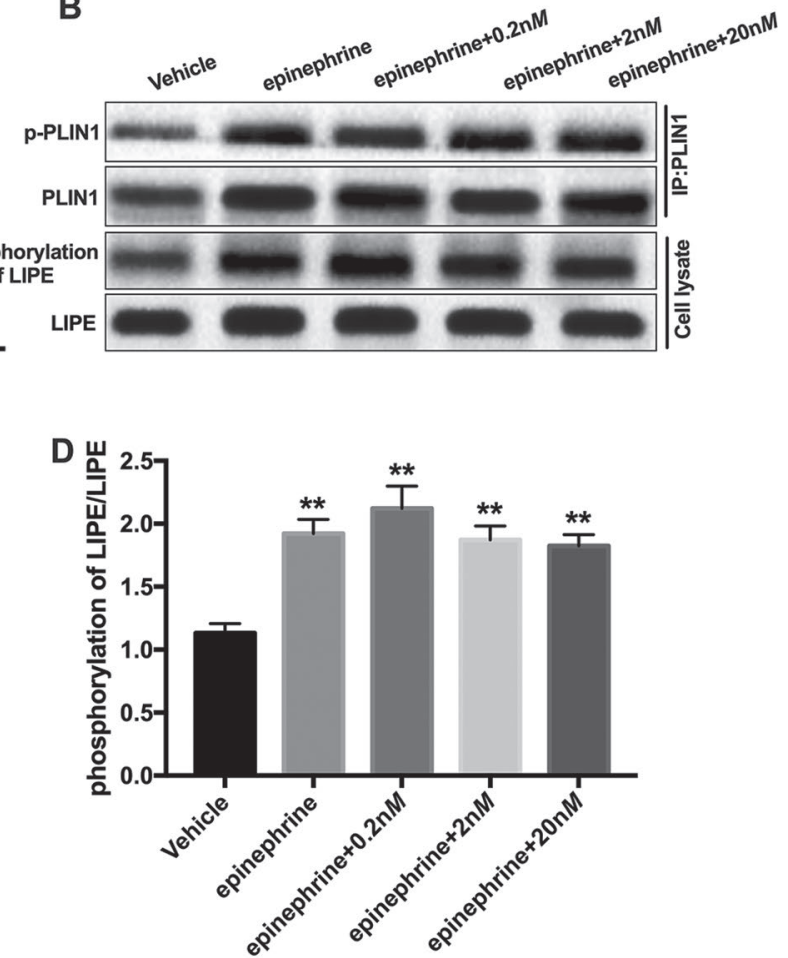

Figure 5. Effects of all-trans retinoic acid (ATRA) treatment on bovine adipocyte lipolysis. (A) Effect of ATRA on basal lipolysis. Fully differentiated adipocytes were treated for $48 \mathrm{~h}$ with ATRA $(0.2,2$, and $20 \mathrm{n} M$ ) or vehicle. (B-E) Effect of ATRA on stimulated lipolysis. Fully differentiated bovine adipocytes were treated with vehicle or ATRA $(0.2,2,20 \mathrm{n} M)$ with or without epinephrine $(1 \mu \mathrm{mol} / \mathrm{L})$. Comparisons among groups were calculated using a one-way ANOVA with subsequent Bonferroni correction. Results represent means \pm SEM for glycerol released per well and are presented as percentage of control. ${ }^{*} P<0.05,{ }^{*} P<0.01$ for treatment versus vehicle group; p phosphorylated.

due to the greater responsiveness to $\beta$-adrenergic and LIPE stimulation (McNamara, 1989; Martin-Hidalgo et al., 1994; McNamara, 1994). In nonruminants, excess lipolysis is a trigger of oxidative stress due to the increase in oxidation of fatty acids leading to excessive production of free radicals that can deplete rapidly antioxidant reserves (Khan et al., 2009). In dairy cows, fatty acids produced by excess lipolysis diminish the immune function of neutrophils and lymphocytes by promoting proinflammatory responses and further reduce their capacity to clear pathogens (Scalia et al., 2006; Ehrhardt et al., 2016). Thus, it is noteworthy that ATRA increased basal lipolysis without affecting hormone-stimulated lipolysis, implying that supply of ATRA might not induce excess lipolysis and further negatively affect performance of peripartal cows. A previous study reported that supplementation of a dose of vitamin A greater than National Research Council recommendations improved immune and antioxidant function in dairy cows, suggesting that vitamin A requirements to ensure immunity and antioxidant function of dairy cows is higher than current recommendations (Jin et al., 2014). Taken together, available data suggest that increased ATRA supplementation in vivo could be effective in prevention and treatment of disorders related to overconditioning during the dry period.

\section{CONCLUSIONS}

Exogenous ATRA acts primarily by reducing preadipocyte proliferation and differentiation, inducing apoptosis, and promoting adipocyte delipidation. Thus, it might help mediate excessive body fat accumulation, providing a theoretical and practical basis for preventing metabolic disorders related to excessive body fat accumulation before parturition. However, an in vivo study is warranted to further demonstrate the role of ATRA in modulating SAT lipid metabolism in overconditioned cows.

\section{ACKNOWLEDGMENTS}

This work was supported by the National Program on Key Research Project of China (Beijing, China; project no. 2017YFD0502206), and the National Natural Science Foundation of China (Beijing, China; grant no. 31672622). The authors have stated no conflicts of interest. 


\section{REFERENCES}

Alric, S., A. Froeschlé, D. Piquemal, G. Carnac, and A. Bonnieu. 1998. Functional specificity of the two retinoic acid receptor RAR and RXR families in myogenesis. Oncogene 16:273-282. https:// doi.org/10.1038/sj.onc.1201484.

Berry, D. C., D. DeSantis, H. Soltanian, C. M. Croniger, and N. Noy. 2012. Retinoic acid upregulates preadipocyte genes to block adipogenesis and suppress diet-induced obesity. Diabetes 61:1112-1121. https://doi.org/10.2337/db11-1620.

Berry, D. C., and N. Noy. 2009. All-trans-retinoic acid represses obesity and insulin resistance by activating both peroxisome proliferation-activated receptor $\beta / \delta$ and retinoic acid receptor. Mol. Cell. Biol. 29:3286-3296. https://doi.org/10.1128/MCB.01742-08.

Blomhoff, R., and H. K. Blomhoff. 2006. Overview of retinoid metabolism and function. J. Neurobiol. 66:606-630. https://doi.org/10 $.1002 /$ neu.20242.

Bonet, M. L., J. Ribot, F. Felipe, and A. Palou. 2003. Vitamin A and the regulation of fat reserves. Cell. Mol. Life Sci. 60:1311-1321. https://doi.org/10.1007/s00018-003-2290-x.

Bonet, M. L., J. Ribot, and A. Palou. 2012. Lipid metabolism in mammalian tissues and its control by retinoic acid. Biochim. Biophys. Acta. 1821:177-189.

Brandebourg, T. D., and C. Y. Hu. 2005. Regulation of differentiating pig preadipocytes by retinoic acid. J. Anim. Sci. 83:98-107. https: //doi.org/10.2527/2005.83198x.

Brasaemle, D. L. 2007. Thematic review series: Adipocyte biology. The perilipin family of structural lipid droplet proteins: stabilization of lipid droplets and control of lipolysis. J. Lipid Res. 48:2547-2559. https://doi.org/10.1194/jlr.R700014-JLR200.

Clarke, S. L., C. E. Robinson, and J. M. Gimble. 1997. CAAT/Enhancer binding proteins directly modulate transcription from the peroxisome proliferator-activated receptor $\gamma 2$ promoter. Biochem. Biophys. Res. Commun. 240:99-103. https://doi.org/10.1006/bbrc .1997.7627.

Dave, S., N. Kaur, R. Nanduri, H. Dkhar, A. Kumar, and P. Gupta. 2012. Inhibition of adipogenesis and induction of apoptosis and lipolysis by stem bromelain in 3T3-L1 adipocytes. PLoS One 7:e30831. https://doi.org/10.1371/journal.pone.0030831.

De Koster, J., W. Van Den Broeck, L. Hulpio, E. Claeys, M. Van Eetvelde, K. Hermans, M. Hostens, V. Fievez, and G. Opsomer. 2016. Influence of adipocyte size and adipose depot on the in vitro lipolytic activity and insulin sensitivity of adipose tissue in dairy cows at the end of the dry period. J. Dairy Sci. 99:2319-2328. https:// doi.org/10.3168/jds.2015-10440.

Ehrhardt, R. A., A. Foskolos, S. L. Giesy, S. R. Wesolowski, C. S. Krumm, W. R. Butler, S. M. Quirk, M. R. Waldron, and Y. R. Boisclair. 2016. Increased plasma leptin attenuates adaptive metabolism in early lactating dairy cows. J. Endocrinol. 229:145-157. https://doi.org/10.1530/JOE-16-0031.

Green, H., and O. Kehinde. 1975. An established preadipose cell line and its differentiation in culture. II. Factors affecting the adipose conversion. Cell 5:19-27. https://doi.org/10.1016/0092 -8674(75)90087-2.

Gregoire, F. M., C. M. Smas, and H. S. Sul. 1998. Understanding adipocyte differentiation. Physiol. Rev. 78:783-809. https://doi.org/ 10.1152/physrev.1998.78.3.783.

Halberg, N., I. Wernstedt-Asterholm, and P. E. Scherer. 2008. The adipocyte as an endocrine cell. Endocrinol. Metab. Clin. North Am. 37:753-768. https://doi.org/10.1016/j.ecl.2008.07.002.

Hausman, D. B., M. Digirolamo, T. J. Bartness, G. J. Hausman, and R. J. Martin. 2001. The biology of white adipocyte proliferation. Obes. Rev. 2:239-254. https://doi.org/10.1046/j.1467-789X.2001 $.00042 . x$.

Hayirli, A., R. Grummer, E. Nordheim, and P. Crump. 2003. Models for predicting dry matter intake of Holsteins during the prefresh transition period. J. Dairy Sci. 86:1771-1779. https://doi.org/10 .3168/jds.S0022-0302(03)73762-X.

Jin, L., S. Yan, B. Shi, H. Bao, J. Gong, X. Guo, and J. Li. 2014. Effects of vitamin $\mathrm{A}$ on the milk performance, antioxidant functions and immune functions of dairy cows. Anim. Feed Sci. Technol. 192:15-23. https://doi.org/10.1016/j.anifeedsci.2014.03.003.

Jump, D. B., D. Botolin, Y. Wang, J. Xu, and B. Christian. 2006. Fatty acids and gene transcription. Food Nutr. Res. 50(Suppl 2):5-12. https://doi.org/10.1080/17482970601069318.

Khan, T., E. S. Muise, P. Iyengar, Z. V. Wang, M. Chandalia, N. Abate, B. B. Zhang, P. Bonaldo, S. Chua, and P. E. Scherer. 2009. Metabolic dysregulation and adipose tissue fibrosis: Role of collagen VI. Mol. Cell. Biol. 29:1575-1591. https://doi.org/10.1128/ MCB.01300-08.

Landrier, J.-F., J. Marcotorchino, and F. Tourniaire. 2012. Lipophilic micronutrients and adipose tissue biology. Nutrients 4:1622-1649. https://doi.org/10.3390/nu4111622.

Lefterova, M. I., and M. A. Lazar. 2009. New developments in adipogenesis. Trends Endocrinol. Metab. 20:107-114. https://doi.org/ 10.1016/j.tem.2008.11.005.

Linhart, H. G., K. Ishimura-Oka, F. DeMayo, T. Kibe, D. Repka, B. Poindexter, R. J. Bick, and G. J. Darlington. 2001. C/EBP is required for differentiation of white, but not brown, adipose tissue. Proc. Natl. Acad. Sci. USA 98:12532-12537. https://doi.org/10 $.1073 /$ pnas.211416898.

Mangiarotti, R., M. Danova, R. Alberici, and C. Pellicciari. 1998. Alltrans retinoic acid (ATRA)-induced apoptosis is preceded by $\mathrm{G}_{1}$ arrest in human MCF-7 breast cancer cells. Br. J. Cancer 77:186191. https://doi.org/10.1038/bjc.1998.32.

Martin-Hidalgo, A., C. Holm, P. Belfrage, M. C. Schotz, and E. Herrera. 1994. Lipoprotein lipase and hormone-sensitive lipase activity and mRNA in rat adipose tissue during pregnancy. Am. J. Physiol. 266:E930-935.

McNamara, J. P., and J. Hillers. 1986. Adaptations in lipid metabolism of bovine adipose tissue in lactogenesis and lactation. J. Lipid Res. 27:150-157.

McNamara, J. P., and K. Huber. 2018. Metabolic and endocrine role of adipose tissue during lactation. Annu. Rev. Anim. Biosci. 6:177195. https://doi.org/10.1146/annurev-animal-030117-014720.

McNamara, J. P. 1989. Regulation of bovine adipose tissue metabolism during lactation. 5. Relationships of lipid synthesis and lipolysis with energy intake and utilization. J. Dairy Sci. 72:407-418. https://doi.org/10.3168/jds.S0022-0302(89)79122-0.

McNamara, J. P. 1994. Lipid metabolism in adipose tissue during lactation: A model of a metabolic control system. J. Nutr. 124(Suppl 8):1383S-1391S. https://doi.org/10.1093/jn/124.suppl_8.1383S.

Mercader, J., L. Madsen, F. Felipe, A. Palou, K. Kristiansen, and L. Bonet. 2007. All-trans retinoic acid increases oxidative metabolism in mature adipocytes. Cell. Physiol. Biochem. 20:1061-1072. https: //doi.org/10.1159/000110717.

Mercader, J., J. Ribot, I. Murano, F. Felipe, S. Cinti, M. L. Bonet, and A. Palou. 2006. Remodeling of white adipose tissue after retinoic acid administration in mice. Endocrinology 147:5325-5332. https: //doi.org/10.1210/en.2006-0760.

Minuti, A., M. Bionaz, V. Lopreiato, N. A. Janovick, S. L. Rodriguez-Zas, J. K. Drackley, and J. J. Loor. 2020. Prepartum dietary energy intake alters adipose tissue transcriptome profiles during the periparturient period in Holstein dairy cows. J. Anim. Sci. Biotechnol. 11:1-14. https://doi.org/10.1186/s40104-019-0409-7.

Moisá, S. J., P. Ji, J. K. Drackley, S. L. Rodriguez-Zas, and J. J. Loor. 2017. Transcriptional changes in mesenteric and subcutaneous adipose tissue from Holstein cows in response to plane of dietary energy. J. Anim. Sci. Biotechnol. 8:85. https://doi.org/10.1186/ s40104-017-0215-z.

Montague, C. T., and S. O'Rahilly. 2000. The perils of portliness: Causes and consequences of visceral adiposity. Diabetes 49:883888. https://doi.org/10.2337/diabetes.49.6.883.

Morrow, D. A. 1976. Fat cow syndrome. J. Dairy Sci. 59:1625-1629. https://doi.org/10.3168/jds.S0022-0302(76)84415-3.

Nedergaard, J., N. Petrovic, E. M. Lindgren, A. Jacobsson, and B. Cannon. 2005. PPAR $\gamma$ in the control of brown adipocyte differentiation. Biochim. Biophys. Acta. 1740:293-304.

Ntambi, J. M., and K. Young-Cheul. 2000. Adipocyte differentiation and gene expression. J. Nutr. 130:3122S-3126S. https://doi.org/10 $.1093 / \mathrm{jn} / 130.12 .3122 \mathrm{~S}$. 
Otto, T., and P. Sicinski. 2017. Cell cycle proteins as promising targets in cancer therapy. Nat. Rev. Cancer 17:93-115. https://doi.org/10 $.1038 /$ nrc.2016.138.

Otto, T. C., and M. D. Lane. 2005. Adipose development: From stem cell to adipocyte. Crit. Rev. Biochem. Mol. Biol. 40:229-242. https: //doi.org/10.1080/10409230591008189.

Ribot, J., F. Felipe, M. L. Bonet, and A. Palou. 2001. Changes of adiposity in response to vitamin A status correlate with changes of PPAR $\gamma 2$ expression. Obes. Res. 9:500-509.

Scalia, D., N. Lacetera, U. Bernabucci, K. Demeyere, L. Duchateau, and C. Burvenich. 2006. In vitro effects of nonesterified fatty acids on bovine neutrophils oxidative burst and viability. J. Dairy Sci. 89:147-154. https://doi.org/10.3168/jds.S0022-0302(06)72078-1.

Schwarz, E. J., M. J. Reginato, D. Shao, S. L. Krakow, and M. A. Lazar. 1997. Retinoic acid blocks adipogenesis by inhibiting C/ EBPbeta-mediated transcription. Mol. Cell. Biol. 17:1552-1561. https://doi.org/10.1128/MCB.17.3.1552.

Spiegelman, B. M., and S. R. Farmer. 1982. Decreases in tubulin and actin gene expression prior to morphological differentiation of 3T3 adipocytes. Cell 29:53-60. https://doi.org/10.1016/0092 $-8674(82) 90089-7$

Spiegelman, B. M., and J. S. Flier. 1996. Adipogenesis and obesity: Rounding out the big picture. Cell 87:377-389. https://doi.org/10 .1016/S0092-8674(00)81359-8.

Strieder-Barboza, C., J. de Souza, W. Raphael, A. L. Lock, and G. A. Contreras. 2018. Fetuin-A: A negative acute-phase protein linked to adipose tissue function in periparturient dairy cows. J. Dairy Sci. 101:2602-2616. https://doi.org/10.3168/jds.2017-13644.

$\mathrm{Su}$, C. L., C. Sztalryd, J. A. Contreras, C. Holm, A. R. Kimmel, and C. Londos. 2003. Mutational analysis of the hormone-sensitive lipase translocation reaction in adipocytes. J. Biol. Chem. 278:43615-43619. https://doi.org/10.1074/jbc.M301809200.

Sumner, J. M., and J. McNamara. 2007. Expression of lipolytic genes in the adipose tissue of pregnant and lactating Holstein dairy cattle. J. Dairy Sci. 90:5237-5246. https://doi.org/10.3168/jds.2007 $-0307$.

Sun, X., X. Li, H. Jia, J. J. Loor, R. Bucktrout, Q. Xu, Y. Wang, X. Shu, J. Dong, R. Zuo, L. Yang, G. Liu, and X. Li . 2019. Effect of heat-shock protein B7 on oxidative stress in adipocytes from preruminant calves. J. Dairy Sci. 102:5673-5685. https://doi.org/ 10.3168/jds.2018-15726.

Theodosiou, M., V. Laudet, and M. Schubert. 2010. From carrot to clinic: An overview of the retinoic acid signaling pathway. Cell. Mol. Life Sci. 67:1423-1445. https://doi.org/10.1007/s00018-010 $-0268-z$.

Tontonoz, P., E. Hu, and B. M. Spiegelman. 1994. Stimulation of adipogenesis in fibroblasts by PPAR $\gamma 2$, a lipid-activated transcription factor. Cell 79:1147-1156. https://doi.org/10.1016/0092 -8674(94)90006-X.
Vanholder, T., J. Papen, R. Bemers, G. Vertenten, and A. C. Berge. 2015. Risk factors for subclinical and clinical ketosis and association with production parameters in dairy cows in the Netherlands. J. Dairy Sci. 98:880-888. https://doi.org/10.3168/jds.2014-8362.

Wan, D. C., Y.-Y. Shi, R. P. Nacamuli, N. Quarto, K. M. Lyons, and M. T. Longaker. 2006. Osteogenic differentiation of mouse adiposederived adult stromal cells requires retinoic acid and bone morphogenetic protein receptor type IB signaling. Proc. Natl. Acad. Sci. USA 103:12335-12340. https://doi.org/10.1073/pnas.0604849103.

Wang, X., P. Yang, J. Liu, H. Wu, W. Yu, T. Zhang, H. Fu, Y. Liu, and C. Hai. 2014. RAR $\gamma$-C-Fos-PPAR $\gamma 2$ signaling rather than ROS generation is critical for all-trans retinoic acid-inhibited adipocyte differentiation. Biochimie 106:121-130. https://doi.org/10 .1016/j.biochi.2014.08.009.

Xu, Q., H. Jia, L. Ma, G. Liu, C. Xu, Y. Li, X. Li, and X. Li. 2019a. All-trans retinoic acid inhibits lipopolysaccharide-induced inflammatory responses in bovine adipocytes via TGF $\beta 1 / \mathrm{Smad} 3$ signaling pathway. BMC Vet. Res. 15:48. https://doi.org/10.1186/ s12917-019-1791-2

Xu, Q., X. Li, L. Ma, J. J. Loor, D. N. Coleman, H. Jia, G. Liu, C. Xu, Y. Wang, and X. Li. 2019b. Adipose tissue proteomic analysis in ketotic or healthy Holstein cows in early lactation. J. Anim. Sci. 97:2837-2849. https://doi.org/10.1093/jas/skz132.

Yang, L., J. Ostrowski, P. Reczek, and P. Brown. 2001. The retinoic acid receptor antagonist, BMS453, inhibits normal breast cell growth by inducing active TGF $\beta$ and causing cell cycle arrest. Oncogene 20:8025-8035. https://doi.org/10.1038/sj.onc.1204911.

Yeaman, S. J. 2004. Hormone-sensitive lipase-New roles for an old enzyme. Biochem. J. 379:11-22. https://doi.org/10.1042/bj20031811.

Zhang, S., G. Liu, C. Xu, L. Liu, Q. Zhang, Q. Xu, H. Jia, X. Li, and X. Li. 2018. Perilipin 1 mediates lipid metabolism homeostasis and inhibits inflammatory cytokine synthesis in bovine adipocytes. Front. Immunol. 9:467. https://doi.org/10.3389/fimmu.2018 .00467 .

Ziouzenkova, O., G. Orasanu, M. Sharlach, T. E. Akiyama, J. P. Berger, J. Viereck, J. A. Hamilton, G. Tang, G. G. Dolnikowski, S. Vogel, G. Duester, and J. Plutzky. 2007. Retinaldehyde represses adipogenesis and diet-induced obesity. Nat. Med. 13:695-702. https:/ /doi.org/10.1038/nm1587.

\section{ORCIDS}

Qiushi Xu (®) https://orcid.org/0000-0003-3012-6475

Juan J. Loor @ https://orcid.org/0000-0003-1586-4365

Yusheng Liang @ (ㄴ) https://orcid.org/0000-0003-1751-6823

Chuang Xu ๑ https://orcid.org/0000-0002-0377-1439 